\title{
QUALITY CONTROL IN FOODS
}

A JOINT meeting of the Association of Public Analysts and the Food Group of the Society of Chemical Industry was held in London during October 3-4 to discuss quality control of food.

The term 'quality control' was intentionally given a very wide interpretation and a diversity of points of view and experience were expressed, including those of the manufacturer, the consumer, and the analyst.

There were three papers concerned primarily with statistics. Dr. E. C. Wood started the series with a relatively simple explanation of the basic concepts, explained many of the terms likely to be used during the symposium, and illustrated simple applications of statistical mothods to experimental results. A later paper by Dr. E. H. Steiner went more deeply into the three main sources of error, those due to analysis, sampling and natural variation, and the separation of errors by the analysis of variance. This included valuable advice on sampling procedures appropriate to situations either where the acceptable degree of risk has been predetermined or where there is no previous knowledge of the variation expected.

Mr. J. H. Harries spoke on the validity of organoleptic tests as a means of quality control. He stressed the importance of putting the right kind of question to taste panels, and illustrated his points by r'efer'ence to a number of score sheots of individual design for the analytical comparison of the qualitios of various foods. He directed attention to the possibility of applying multivariate analysis to an examination of the step volues in arbitrary scales, and also referred to techniques for avoiding numerical intervals without losing the advantages of statistical interpretation of the data obtained.

A paper on the practical application of statistics to the bacteriological control of canned meats, by Dr. H. Riemann, of the Dunish Meat Research Institute at Roskilde, was rear by his colleague, Mrs. E. Blomquist, who later gave a paper of hor own on another practical example of statistical quality control in the production of luncheon meat. The former directed attention to the relation between batch size, the number of samples tested and the degree of confidence with which it could be assumed that the samples gave an accurato measure of the bacterial quality of the batch. It was pointed out that the sampling methods discussed might give at good picture of general quality, but to safeguard against the occurrence of such dangerous organisms as Clostridium botulinum, the number of samples necessary might be unpractical. A most careful watch on raw materials and ingredients and efficient supervision of processes were necessary. The example described in Mrs. Blomquist's paper, although mainly concerned with the mathematics of variations in tare and net weight of cans and the operation of quality control charts, also dealt with some of the practical details, and indicated that such methods are worth while if the findings are used appropriately by the management, and can then be of considerable financial benefit.

Six of the papers were given by technologists from different branches of the food industry. Dr. A. G. lipscomb described the practical application of quality control methods in the chocolate and confectionery industry. It is necessary" to ensure that raw materials conformed to specification in com. position and were of the expected flavour; propor. tioning and processing must be kept within budget limits ; the product must reach the stendard expecterl by the consumer and have an adequate shelf-life without loss of appearance or flavour. Physical assessments such as determinations of fat or the particle size in chocolate lend themselves to statistical treatment and to the use of quality charts as a means of judging performánce. Comparisons of means and deviations could be utilized to diagnose errors in machine settings. Subjective assessment of raw materials and finished products is essential. Practical advice on experiment design and the management of taste panels was given. The intersection of the curves of cost of production and sale price when plotted against quality show only a restricted ares of profitable operation, so quality control alone does not ensure dividends.

Dr. W. B. Adam said that fruit and vegetable can. ner's made only limited use of statistical methods in routine control, but nevertheless such methods had been valuable for specific investigations. He referred particularly to the variability of can weights and filled weights, and the difference between the original weight of fruit in a can and the subsequent drained weight. Subjective assessment, allied to suitably designed score cards, is of great assistance in recording the quality of canned fruit or vegetables, but experienced buyers rely on mental integration of their observations rather than on mathematical calcula. tions. Mechanical aids such as the tenderometer used for forecasting the optimum maturity of a pea orop were briefly described and explained.

Dr. R. J. MacWalter spoke on quality control in milk and dairy products. The relations between producer and buyer of milk are somewhat unusual, since apart from the brief judgment of an expert nose the quality of milk is probably not known until after it has been accepted, bulked, pasteurized and passed on. Nevertheless, a number of tests are applied to samples before distribution to ensure conformity with legal requirements, efficiency of heat treatment, freedom from contamination and control of measure in bottle. Reference was made to the problems of sampling evaporated or sterilized milk products in order to reach an adequate degree of assurance that the product is safe and the spoilage rate minimized. Grading methods for cheese and butter wero mentioned. A graphic illustration was given of the relationship between bacterial contamination counts and standards of factory hygiene in rival creameries.

Quality control of open packed meat products was discussed by Mr. S. Brightwell. Variability in availability of raw material complicates the maintenance of uniform quality in sausages. Several sensory qualities by which they are judged such as juiciness, texture and flavour-are not easily assessed numerically or given definite weighting. It is important to trace the causes of reported variations in quality. It was noted that tasters' views on saltiness do not necessarily agree with chemical analyses, and a seasonal variation in the sensitivity of panels to saltiness was mentioned. A sensory assessment by an expert might be accepted in preference to \& laboratory report where these were in conflict. 
It is difficult to measure dough so accurately that after baking all loaves or all biscuits will fall within a narrow weight-range. Dr. R. Falconer described how control charts could profitably be used to give warning that re-adjustment of machines was desirable, and spoke of the possibility of extending the application of appropriate methods to other observations necessary for good management in the baking industry.

The fish industry depends in no small measure on the Department of Scientific and Industrial Research for technical guidance. Industry has felt a need for better methods of control of quality, and practical help has been given by introducing well-organized subjective assessments and by compiling scientific data. Dr. C. L. Cutting mentioned in particular a system of grading kippers which the industry has welcomed and which may lead to improved quality. The occurrence of parasitic worms in fish from certain fishing grounds has been studied statistically and constructive recommendations formulated.

An interesting paper from quite a different aspect of the subject was given by Dr. R. A. Scott on the automatic control of proportioning and mixing. $\mathrm{He}$ gave details of practical methods of measuring liquids and powders, and of various types of automatic weighing and delivery devices, culminating in explanatory diagrams of fully automatic plant for weighing, delivering and mixing six or more ingredients according to formulæ fed to a control panel on a punched card. In such systems there are devices designed to eliminate as many as possible of the known causes of undesirable variation.

The factory manager's outlook on quality control was indicated by Mr. M. Bogod. Such control is welcome where it is an aid to economical production, improved service to customers or conformity with legal obligations. So far as possible, interference with the flow of production should be avoided. Sometimes the nature of the control can be designed so that automatic adjustments can be made to correct undesirable trends. Great importance is attached to cordial co-operation from operational and supervisory staff. This can be achieved only where they understand how quality control can improve matters. The spot judgment of expert individuals is usually preferable to that of taste panels in detecting deviations from the normal in flavour or appearance.

Public analysts exercise quite a different form of quality control. Mr. E. G. Whittle expressed their point of view. They are concerned first with compliance with legal requirements, and secondly that foods conform to what the customer is led to expect. It is often difficult to decide desirable limits of variation of quality in foods, but the Association of Public Analysts has a part in helping the Foods Standards Committee to reach conclusions on these matters. Statistics have been valuable to analysts in agreeing on the natural limits for the freezing point of milk and to a lesser extent in accounting for the effects of natural variation in raw materials used in food such as jams. The work of a magistrate's court would not, however, be made easier if a public analyst expressed his findings in terms of statistical probabilities.

Mr. D. H. Pickard brought to the symposium his views on quality as a market research worker. He pointed out that the consumer in his judgment of quality uses very different criteria from those of the manufacturer or public analyst. They are influenced not only by the inherent qualities of a food product but also by imputed qualities. Appearance, for example, affects taste discrimination. Imputed qualities may sometimes appear to be irrational, but they are of real importance. Mr. Pickard described statistical methods of market research which are relevant to ascertaining consumers' ideas of quality. The importance of directing research to the asking of the right questions was illustrated.

There was a short discussion at the end of each session and a general discussion on the last afternoon before Dr. A. J. Amos gave a final summing up.

It was evident that not all food technologists were expert in mathematics, and the suggestion naturally arose that opportunities should be provided for teaching them statistics. It was agreed that the various forms of quality control used should be explained to all production personnel. The colleges of food technology teach students these methods, but factory staff in general can best be reached by instruction given within their firms.

The advantages of early consultation with statisticians in the design of experiments was recognized. Co-operation between statisticians and food technologists might be necessary when using the lesssimple techniques and both should know something of the others' subject. In some factories quality control has led to the elimination of excessive overweight once necessary to compensate for possible inaccuracies, and reduced costings have more than offset the cost of control.

Fatigue and bias among tasters were discussed. For some routine purposes fatigue did not reach eritical importance, but where special discrimination was needed the number of samples compared should be small, possibly not more than two or three at a session.

In checking the composition of products such as jams or meat or fish pastes, analysts allow for some variation in the composition of raw materials. Manufacturers sometimes find that quite genuine raw materials occasionally fall short of the usual lower limits for some characteristic, and they suggest that analysts should therefore take wider limits as a basis for their calculations. Publie analysts, on the contrary, suggest that raw material should not be used if it is of abnormally poor quality, however genuine. A fear was expressed that the setting of minimum standards may cause a decline of average quality towards that minimum. Although it was suggested that the need for standards was sometimes over-emphasized, the general view seemed to be that standards usefully show what the most indiscriminating customer has a right to expect, but do not necessarily represent what the discriminating customer wants. The manufacturer may be tempted by the complaisant consumer into a debasement of quality, and the analyst must strengthen the resolution not to succumb. Some quality-conscious people may be difficult to satisfy because their tastes. are not sufficiently widely shared. It would be regrettable if standardization, in protecting the hoedless, reduces the competition between manufacturers, thus depriving the good housewife of the pleasure of exercising individual skilful selection.

This symposium undoubtedly helped participants to realize that both public analysts and food manufacturers are interested in their own ways in service to the public. Co-existence may be the happier as a result of better appreciation of the reasons underlying each other's actions. 